\title{
INTRODUCTION
}

\section{Science in the Time of COVID-19}

With the arrival of the pandemic, scientists from every country rearranged their priorities, and Argentina was not the exception. A myriad of scientific papers of variable quality were produced all over the world, and rushed for publication on the knowledge that in lieu of prompt diffusion many would have soon become obsolete. Science Reviews from the end of the world was very cautious; after all we publish only reviews of significant work, often carried out during long time spans.

Controversy has arisen on the validity of mathematical models to describe the spread of the pandemic, on the testing procedures and the ways to achieve significant tracking of the spread of the virus, on the validity of various therapies, on the nature and performance of various vaccines, on social and political issues about lockdown policies, etc.

In this issue we present just two papers, addressing the first issues in the above paragraph, mathematical models and testing strategies. They represent very thorough work that had clear application in the design of pandemic management in Argentina. Papers of equivalent quality on the other issues have been commissioned, and shall be published when available.

The research teams led by Guillermo Durán and by Roberto Etchenique represent well the paradigm of current research, as the result of the effort of multidisciplinary teams focused on problem solving.

We hope these papers prove of value to all readers.

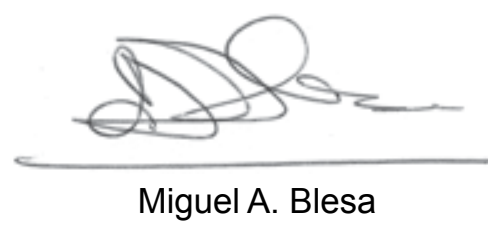

\section{Bio}

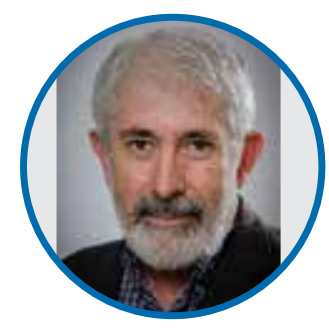

\section{Miguel A. Blesa}

$\mathrm{Ph} \quad \mathrm{D}$ in Chemistry, La Plata University. Formerly: Chemistry Manager (Atomic Energy Commission); Federal Undersecretary of Science and Technology; Senior Researcher (CONICET); Full Professor (San Martín University); President (Argentine
Associaition for the Advancement of Science). Past President, Interciencia Associaition. Member of the National Academy of Science (Córdoba), National Academy of Exact, Natural and Physical Sciences (ANCEFN) and Academy of Sciences of Latin America. TWAS Prize in Chemistry (2004). Konex Merit Diploma in Chemsitry (2003). President for Argentina in the Bilateral French Argentine Cooperation Program (ECOS-SUD). Main research interests: chemistry of metal oxide particles immersed in water; environmental chemistry. 